\section{Anti-drug antibodies}

\author{
Clemens Warnke, ${ }^{1,2}$ Christina Hermanrud, ${ }^{1}$ \\ Malin Lundkvist, ${ }^{1}$ Anna Fogdell-Hahn ${ }^{1}$ \\ ${ }^{1}$ Karolinska Institutet, Department of \\ Clinical Neuroscience, Center for \\ Molecular Medicine, Karolinska University \\ Hospital, Stockholm, Sweden; \\ 2Department of Neurology, Medical \\ Faculty, Heinrich-Heine-University \\ Düsseldorf, Germany
}

\begin{abstract}
Biological pharmaceuticals are increasingly used in modern medicine and give remarkable improvements for many different patient groups. Unfortunately, for several of these compounds, undesirable immune reactions are induced against the drug. The resulting anti-drug antibodies modify the pharmacokinetic and pharmacodynamic properties of the drug and, by blocking the drug-target interaction, reduce the effects of the treatment. Antidrug antibodies may also increase the risk of hypersensitivity reactions by the formation of immune complexes. Furthermore, by crossreacting with the endogenous homolog of the drug, the anti-drug antibodies might impair important physiological functions even after treatment cessation. As a consequence, antidrug antibodies need to be taken in account when estimating the benefit-burden ratio of a treatment for an individual patient, but also when calculating the value of therapeutics on a socio-economic level. In this review we give an overview over the current understanding of the immunogenicity against drugs, exemplified for patients with hemophilia A, multiple sclerosis, rheumatoid arthritis and Crohn's disease. We discuss known and potential risk factors for anti-drug antibody formation and finally outline suggested strategies for prediction and prevention.
\end{abstract}

\section{Introduction}

The successful identification of important molecular interactions contributing to disease pathogenesis have led to the promising development of several biological pharmaceuticals (BPs), of which many have shown to be highly efficient treatments in clinical trials as well as in the post-marketing settings. These compounds can be designed to supplement missing factors [e.g. factor VIII for hemophilia A (HA) ], to interfere with pathological processes by immunomodulation [e.g. interferon beta
(IFN $\beta$ ) for multiple sclerosis (MS)] or by blocking pathogenic signaling [e.g. anti-tumor necrosis factor alpha (TNF $\alpha$ ) therapeutics for rheumatoid arthritis (RA) or Crohn's disease (CD) and the anti-integrin therapy in MS or CD]. The quite specific mode of action of several BPs is promising, as physiological functions are mainly preserved, but pathological processes successfully targeted or replaced. However, the chronic nature of many of these diseases will require repetitive parenteral administration for life. This results in the risk of undesirable immune responses against the drug, leading to the formation of anti-drug antibodies (ADA). One major concern for clinicians is the loss of response (LOR) to the treatment due to the formation of ADA. The LOR can be due to two non-exclusive mechanisms. First, all ADA that bind to the BP, also referred to as binding antibodies (BAbs), can alter pharmacokinetic properties of the agent by forming immune complexes with the drug. These immune complexes can enhance the clearance of the drug from the circulation, and thus potentially the effective dosage of the treatment. ${ }^{1}$ Second, so-called neutralizing ADAs (NAbs), which is essentially higher affinity BAbs, can directly interfere with the biological activity of the drug by binding to epitopes that lie within the active site or by steric hindrances of sites in close proximity to it. ${ }^{2} \mathrm{An}$ additional concern with ADA-formation is the increase of adverse effects, which is negatively impacting the benefit-risk ratio of a therapy. For example, immune complexes of ADAs with BPs have been associated with an increased risk of type III hypersensitivity reactions. ${ }^{3}$ Furthermore, when a biological therapeutic supplements an endogenous homolog, ADAs against the pharmaceutical could potentially also target the endogenous homolog, with unforeseeable consequences for physiological functions even long after treatment cessation. ${ }^{4}$ An illustration of this potential complication is the case reports of severe thrombocytopenia or pure red cell aplasia induced by anti-thrombopoietin or anti-erythropoietin NAbs that cross-react with the corresponding endogenous protein. ${ }^{5-7}$ Thus, the risk of ADA-formation needs to be taken in account when estimating the benefit-burden ratio of a treatment for an individual patient, and when calculating the value of a therapeutic on a socio-economic level, but preferentially already during drug development. ${ }^{8}$

In this review we discuss the immunological mechanisms involved in ADA-formation, the current methods used to detect ADAs, and outline a perspective to predict, prevent and deplete ADAs. In each section we provide examples from three different clinical fields: first, the treatment of HA with more than 50 years of experience with so called factor VIII inhibitors $;{ }^{9}$ second, the treatment of MS where
Correspondence: Anna Fogdell-Hahn, Department of Clinical Neuroscience, Center for Molecular Medicine, Karolinska Institutet, Stockholm, Sweden.

E-mail: anna.fogdell-hahn@ki.se

Key words: anti-drug antibodies, neutralizing antibodies, binding antibodies, biological pharmaceuticals, immunogenicity, multiple sclerosis, NAb, BAb, ADA.

Funding: this work was supported by an ECTRIMS fellowship stipend to $\mathrm{CW}$.

Received for publication: 13 March 2012.

Revision received: 31 May 2012.

Accepted for publication: 31 May 2012

This work is licensed under a Creative Commons Attribution NonCommercial 3.0 License (CC BYNC 3.0).

(C) Copyright C. Warnke et al., 2012

Licensee PAGEPress, Italy

Drugs and Therapy Studies 2012; 2:e11

doi:10.4081/dts.2012.e11

the detection of ADAs were noted already within the first pivotal trials for disease modifying $\mathrm{BPs} ;{ }^{10}$ and third, the treatment of RA and CD as examples from a field where the clinical relevance of ADAs is controversial, partly due to a lack of standardized methods to assess immunogenicity. ${ }^{11,12}$

\section{Immunological mechanisms involved in anti-drug antibody-formation}

The frequencies of ADA positivity differ largely for different treatments and this is partly explained by the degree of immunological tolerance that exists naturally. For BPs with high bio-similarity to proteins encoded in the human genome, it would be expected that the immune system should tolerate the BP equally well as the corresponding self-proteins. Tolerance to a BP is regulated by central and peripheral immunological mechanisms and is dependent on the formation and activation of BP specific T- and B-cell clones and deletion of self-reactive clones. In the thymus the central tolerance eliminates immature T cells expressing T-cell receptors that form high-avidity interactions with self-peptides presented in the context of human leukocyte antigen (HLA). ${ }^{13}$ This T-cell maturation step will ensure that most self-reactive T-cell clones are deleted.

In patients with HA there is most likely low or non-existing tolerance to factor VIII, since the 
disease in itself is due to the lack of this protein. Probably several factor VIII specific T-cell clones have escaped the central tolerance and are present to cause a classical T-cell dependent activation of B cells, leading to ADA-formation, when the therapy starts. ${ }^{14,15}$ This is a considerable risk with replacement therapies, where genetic deficiency or a defect in the endogenous protein causes the disease. For HA patients with factor VIII treatment a high frequency of ADA, or inhibitors as they are termed in this field, is formed. ${ }^{15,16}$ These are predominately of the high-affinity immunoglobuline G (IgG) isotype, mainly of the IgG4 subclass, indicating a T-cell dependent B-cell activation. ${ }^{15}$ In accordance with that, the risk of ADA-formation is strongly influenced by the underlying factor VIII mutation, with higher immunogenicity seen in patients with nonsense versus missense mutations. ${ }^{15,17,18}$

While it might not be unexpected that antibodies are formed against substances that the immune system has never encountered before, ADAs are also formed against proteins that we normally are tolerant against and which have been part of the central tolerance. This can be explained by a breaking of the peripheral tolerance. ${ }^{19}$ Since not all peptides of every self-protein can be expressed in thymus, a proportion of self-reactive $\mathrm{T}$ cells will still escape to the periphery. This is usually not a problem, since the peripheral tolerance ensures that naïve $\mathrm{T}$ cells only become activated by dendritic cells (DCs) when they are provided with both the antigen specific peptide-HLA complex and proper co-stimulatory signals. ${ }^{20}$ DCs will express these co-stimulatory molecules when they sense danger through the stimulation of pattern recognition receptors. ${ }^{21}$ These receptors are activated by pathogens, but also by tis- sue damage. Thus, the disturbance of the integrity of the tissue due to repetitive injections of BPs and components present in bacterial-derived drug preparations are both factors that might activate DCs.

Several types of DCs build a network of surveillance in the skin, of which the CD14+ DCs have been indicated to play an important role in induction of the humoral immunity against compounds injected subcutaneously.22 These DCs are the main activator of T cells specialized to prime naïve $\mathrm{B}$ cells and individual variations on the presence of this DC subtype might be important determinates of ADA induction. The sustained quantities and qualities on the circulating ADA is probably influenced by the phenotypes of $\mathrm{T}$ and $\mathrm{B}$ cell subsets. As an example the CXCR5 ${ }^{+} \mathrm{CD} 4{ }^{+} \mathrm{T}$ follicular cells are most capable of activating germinal center B cells to induce high-affinity isotype-switched IgGs and efficient B-cell memory responses. ${ }^{23,24}$ Thus, individual variations, activation and regulation of lymphocytes and DC subsets might be most critical for ADA formation against injectable drugs.

Patients with MS that express normal levels of endogenous IFN $\beta$ protein receive treatment with an IFN $\beta$ homolog that they ought to be tolerant against, but yet ADAs are formed in these patients. In this case, two non-exclusive different mechanisms could be envisioned to be involved in ADA-formation, the T-cell dependent and the T-cell independent activation of $B$ cells. The repetitive stimulation of DCs at the injection sites will eventually lead to the uptake and presentation of IFN $\beta$ peptides in lymph nodes by the DCs, a site where IFN $\beta$ do not appear normally. Therefore silent IFN $\beta$-specific T-cell clones become activated and can give the help that IFN $\beta$-specific $B$ cells need to become ADA producing cells. This T- cell dependent B-cell activation will lead to the high-titer ADA-production of antibodies with high affinity.

The T-cell independent B-cell activation can be induced by aggregates of IFN $\beta$ cross-linking B-cell receptors by repetitive structures. ${ }^{14,25}$ Although cross-linking of B-cell receptors in the first place leads only to the formation of low-affinity immunoglobuline M-antibodies, the presence of additional stimulating factors such as B-cell activating factor (BAFF) or interferon are discussed to allow marginal center zone B cells - the effector B cells of the T-cell independent antibody production - a limited switch to $\operatorname{IgG}$, and potentially also the induction of memory responses. ${ }^{14}$ Both these mechanisms are probably involved when ADA is formed in IFN $\beta$ treated patients, although to different extent depending on the preparation, which will be discussed later.

Anti-TNF $\alpha$ is an approved drug for RA and/or CD and include infliximab, etanercept and adalimumab. As infliximab is a chimeric murine-human IgG1 monoclonal antibody, the T-cell dependent B-cell activation toward a neo-antigen as outlined above might explain the comparable high immunogenicity (Table 1). ${ }^{26}$ Etanercept is a humanized IgG1 Fc fragment fused to two identical humanized TNFreceptors, demonstrating lower immunogenicity. ${ }^{11}$ Nevertheless, for adalimumab, a purely humanized IgG1 antibody, conflicting data on ADA-frequency has been published $[<1 \%$ to $87 \%$ (Table 1),${ }^{27}$ highlighting the fact that not only homology to human sequences, but also other risk factors discussed below as well as the ADA assay used, are critical to the reported immunogenicity.

Natalizumab, a humanized IgG4 antibody that targets the $\alpha 4$-subunit of two different

Table 1. Immunogenicity of different biological pharmaceuticals.

\begin{tabular}{|c|c|c|c|c|}
\hline Drug & Route & Indication & Frequencies (\%) & Clinical relevance and comments \\
\hline Factor VIII & s.c.; i.v. & $\mathrm{HA}$ & $0-33^{15,16,28}$ & $\begin{array}{l}\text { Highly relevant, high frequency in patients with severe HA, LOR associated } \\
\text { with potentially life-threatening complications }\end{array}$ \\
\hline $\begin{array}{l}\text { IFN } \beta \\
-1 b \\
-1 a \\
-1 a\end{array}$ & $\begin{array}{l}\text { S.c. } \\
\text { S.c. } \\
\text { i.m. }\end{array}$ & MS & $\begin{array}{l}28-47^{* 25} \\
5-38^{* 25} \\
2-14^{* 25}\end{array}$ & $\begin{array}{l}\text { Immunogenicity different for different IFN } \beta \text {-preparations, high titers of NAbs } \\
\text { associated with LOR, role of low titer NAbs or BAbs controversial }\end{array}$ \\
\hline Natalizumab & & $\begin{array}{l}\text { MS } \\
\text { CD }\end{array}$ & $\begin{array}{c}2,4-6^{\circ} \\
6-9,5^{\circ} 29,30\end{array}$ & $\begin{array}{l}\text { Comparable low frequency in post-marketing studies, association with } \\
\text { infusion-related side effects, testing highly standardized, assay does not } \\
\text { detect monovalent antibodies }\end{array}$ \\
\hline $\begin{array}{l}\text { Anti-TNF } \alpha \text { BPs } \\
\text {-Infliximab } \\
\text {-Etanercept } \\
\text {-Adalimumab } \\
\text {-Infliximab } \\
\text {-Adalimumab }\end{array}$ & $\begin{array}{l}\text { i.v. } \\
\text { S.c. } \\
\text { S.c. }\end{array}$ & $\mathrm{CD}$ & $\begin{array}{c}8-44^{31-34} \\
0-5,6^{35-38} \\
<1-87^{39-44} \\
\\
6-67^{45-49} \\
2,6-177^{50,51}\end{array}$ & $\begin{array}{l}\text { LOR and increase of the therapeutic dosage established for infliximab, } \\
\text { association with infusion-related side effects, testing not standardized, } \\
\text { concomitant treatment and dosage shown to highly impact frequency of } \\
\mathrm{ADA}^{31}\end{array}$ \\
\hline
\end{tabular}

HA, hemophilia; MS, multiple sclerosis; RA, rheumatoid arthritis; s.c., subcutaneously; i.m., intramuscular; MRI, magnetic resonance imaging; NAbs, neutralizing antibodies; BAbs, binding antibodies; CD, Crohn's disease; LOR, loss of response; i.v., intravenously; ${ }^{*}$ frequency of NAbs; ${ }^{\circ}$ persistent positives only. 
integrins, ${ }^{27}$ induces ADAs in patients with MS or CD to some extent, but these numbers are considerably lower compared to the immunogenicity of other BPs in the treatment of the same diseases. Thus, the degree of reaction the immune response will elicit against a specific BP will be influenced by both the molecular structure of the BP and the tolerance state of the patient. There are however several additional factors, as discussed next, that influence immunogenicity of a drug and the frequency of ADA on a population level (Table 1).

\section{Risk factors for the development of anti-drug antibodies}

The variety of risk factors that will determine the level of immunogenicity of a certain BP includes the molecular composition of the drug, the mode of administration, genetic factors, the disease treated, the dosage of the BP, the concomitant medication, and so far undefined variables. These multitude of factors explain why only a proportion of patients develop ADAs. ${ }^{19}$

\section{Characteristics of the biological therapeutics}

Product related factors include the degree of homology to endogenous proteins as discussed before. This, however, is not restricted to foreign or chimeric BPs; also for humanized BPs variations in sequences are known to influence the immunogenicity. ${ }^{25}$ The incidence of ADA-formation is partly dependent on the affinity of peptides to HLA, where some BP-formulations containing immunodominant peptides binding to common HLA alleles will give a higher incidence of ADA. ${ }^{52}$ In addition, posttranslational modifications such as glycosylation have been shown to impact ADA-formation. In general, non-glycosylated variants are more immunogenic than glycosylated proteins, probably contributing to the higher immunogenicity of bacteria-derived IFN $\beta$-1b compared with mammalian-cell derived IFN $\beta$-1a (Table 1) and partly explained by the formation of protein aggregates. ${ }^{19}$ Interestingly, factor VIII is a glycoprotein and the immunogenicity varies dependent on what sugar residues are coupled to the protein. Mannosylation of factor VIII alleviates the receptor mediated endocytosis by DCs, and thus is associated with a higher probability to activate T-cell dependent ADAformation..$^{53}$ Contaminants and process-related impurities can also contribute to immunogenicity, e.g. illustrated by the observation of a sudden increase in immunogenicity of a factor VIII preparation after changes in the production process. ${ }^{54}$ In addition, formulations and storage might impact immunogenicity, as these factors can influence the amount of aggregates being formed. ${ }^{19}$

\section{The mode and the frequency of administration}

A higher frequency of administration increases the risk of ADA-formation compared with an acute therapy. ${ }^{19}$ The only once weekly intramuscular injected IFN $\beta$-1a seems to carry the lowest risk of ADA-formation among the two different IFN $\beta$-1a preparations. ${ }^{55}$ For factor VIII and IFN $\beta$ the subcutaneous administration is considered more immunogenic compared with the intravenous and intramuscular administration, respectively. 55,56 This seems not to be true for anti-TNF $\alpha$ BPs, although this comparison is compromised by the chimeric character of infliximab (Table 1).

\section{The genetics of the individual, and the diseases treated}

The genetic influence in ADA-formation is evident when patients, due to a genetic deficiency, lack the expression of a normal endogenous protein. These patients are expected not to be tolerant to the $\mathrm{BP}$, resulting in high rates of $\mathrm{ADA}$ formation in severely affected patients with HA. ${ }^{57}$ However, also in tolerant patients the genetics influence the immunogenicity. Several genetic studies in different fields have shown an HLA association between different BPs and the formation of ADAs. The HLA molecules are highly polymorphic, ${ }^{58}$ and not all peptides of a drug will bind to all HLA alleles. Thus, both the amino acid composition of the drug, and the HLA haplotype of the patients are likely to influence the risk of developing ADAs. For MS patient treated with IFN $\beta$ several associations between certain HLA class II haplotypes and ADA-development has been reported. ${ }^{52,59,60}$ Interestingly, the difference between the reported ADA-associated alleles, DRB $1 * 04: 01$ and *04:08, and the protective alleles, DRB1*04:02, DRB1*04:03 and DRB1*04:04, was only one amino acid in position 86 at the end of the alpha helix. This indicates that a single binding motif might have large impacts on which agretopes of IFN $\beta$ are presented. No difference was observed when looking at BAbs and NAbs separately, suggesting that the HLA-polymorphism might be important for triggering the presence of ADAs, but less important for the affinity maturation. ${ }^{59,60}$ Not only in MS, but also for factor VIII treated patients with HA, several class II HLA associations have been found, although these seem to be comparable weak. ${ }^{17}$ In addition, certain polymorphisms in non-HLA genes, such as TNF $\alpha$, IL10 , and CTLA-4 in HA, ${ }^{61}$ or in proximity to a protein kinase gene and a gene involved in signal transduction pathways in MS patients treated with $\operatorname{IFN} \beta$, have been linked to ADA-formation. ${ }^{62}$
The HLA associations are probably highly dependent on the protein sequence of the BPs; thus, not necessarily the same HLA association can be expected to increase the risk of ADAformation for different BPs, or different variants of a class of BPs. However, some of the non-HLA associations regulating ADA-formation could potentially predispose for developing antibodies against several BPs. Although this has not yet been studied in a comprehensive manner, at least in MS patients switched from IFN $\beta$ to natalizumab, no increased risk of ADA-formation toward both IFN $\beta$ and natalizumab were found, indicating different genetical susceptibility factors for ADA induction towards different BPs. ${ }^{63}$

The underlying disease of the treated patient might have an impact on ADA-formation. In HA, the causative factor VIII mutation strongly influences the risk of $\mathrm{ADA}$ (e.g. nonsense versus missense mutations).${ }^{17}$ In addition, the excess bleeding is thought to give a state of chronic inflammation. This might result in a general unspecific activation of the immune system, increasing the risk of ADA-formation. This principal is supported by experimental data showing lower immunogenicity for factor VIII replacement therapy when animals were treated with the anti-inflammatory agent Hemeoxygenase-1 (HO-1) before the injection. ${ }^{64}$ Similarly, one can hypothesize that IFN $\beta$, which in itself stimulates the immune response, and the heightened inflammation status of MS patients, both to some extent contribute to the risk of ADA-formation.

\section{Concomitant medication and the dosage of the biological pharmaceutical}

Mainly for TNF-antagonists the dosage as well as the administration of concomitant medication - such as methotrexate - has been shown to impact immunogenicity. Higher dosage might induce tolerance, and immunosuppressive co-medication suppresses the activation of antibody-producing B cells, both resulting in lower ADA frequency. ${ }^{31}$ In MS the combined administration of IFN $\beta$ and pulse methylprednisolone therapy can reduce ADA development in IFN $\beta$ nä̈ve individuals. ${ }^{65}$

\section{Methods to detect anti-drug antibodies}

The difference in ADA frequencies reported for the same BP in different studies can also be explained by the method used to detect the antibodies (Table 1). Assays for determining seroprevalence and immunogenicity need to detect all binding ADAs, but also to assess the frequencies and quality of their neutralizing capacity. 
Typically, immunoassays are used to screen for ADAs. ${ }^{66}$ Samples tested positive in the immunoassay for ADAs are subsequently tested in an in vitro cell-based bioassay or a non-cell based competitive ligand binding assay to determine the neutralizing capacity. $1,2,67$

\section{General assay principles for screening of anti-drug antibody presence}

Conventional screening assays such as enzyme linked immunosorbent assay (ELISA) and radioimmunoassay (RIA) are widely used for detection of ADAs. ELISAs are rapid, robust and easy to perform, allowing for high throughput screening. Different methods such as direct, indirect, and bridging ELISAs can be applied. ${ }^{67}$ In the bridging assay the antibody is captured by the solid-phase-bound antigen and visualized by the labeled antigen. ${ }^{68}$ Since the antibody is recognized twice this results in higher specificity. ${ }^{67}$ This can be applied with or without radioimmunolabeling. A disadvantage of the bridging ELISA and radiolabeling techniques, however, is that they cannot distinguish between BAbs and NAbs. Therefore, these assays cannot tell what percentage of the antibodies detected are neutralizing and actually have direct implications on the binding of the drug to its target. Moreover, the restricted use of radioactivity limit the use of the RIA assays in clinical routine testing.

\section{General principles of neutralizing antibody assays}

In vitro neutralizing antibody assays are the methods that characterize the ability of ADAs to antagonize the biological effect of a BP. For most of the BPs, NAbs are currently studied in cell-based bioassays in which treated cells respond directly or indirectly to the $\mathrm{BP}$ in a dose-dependent manner and then this reaction is blocked in presence of the patients sera if these contains neutralizing ADA. ${ }^{67}$ Readouts will be different for varies assays (e.g. proliferation, apoptosis, or mRNA expression), and the design needs to reflect the agonistic or antagonistic character of the BP. One example for a recently developed cell-based technique is the luciferase reporter gene-expression assay. In this method a cell-line is used in which a firefly luciferase gene is coupled downstream to the promoter region of the target of interest lying downstream of the receptor stimulated by the drug. In case NAbs are present in the serum of the patient, they will interfere with e.g. a blocking BPs such as a TNF-antagonist, which consequently will result in a higher luciferase activity induced by added soluble TNF. ${ }^{69}$ Whatever system is used to study NAbs, an extensive validation is required to acquire reproducible and reliable analyses for clinical routine. As cell-based assays are time consuming, attempts to replace these assays with noncell based competitive ligand-binding assays to study the neutralizing capacity of ADAs are considered for some of the BP.67

\section{Examples of techniques currently used in hemophilia, multiple sclerosis, rheumatoid arthritis and Crohn's disease}

The inhibitors in HA are predominantly measured by the Bethesda quantitative assay and the Nijmegan assay. In both techniques the residual factor VIII activity is quantified after mixing a patient plasma sample with plasma containing a standardized defined amount of factor VIII. ${ }^{70}$

Binding and neutralization assays are subsequently applied to detect ADAs to IFN $\beta$ in patients with MS. Direct ELISAs are most commonly used in the first step to detect BAbs present in the serum of patients,${ }^{71}$ although bridging- or double antigen ELISA techniques have been recently described. ${ }^{72}$ However, these assays detect ADA in up to $70 \%$ of the patients which does not necessarily reflect their clinical relevance. Therefore several cell-based bioassays have been developed to determine the neutralizing capacity of BAbs. The most widely used techniques study the inhibitory effect of $\operatorname{IFN} \beta$ in the presence of patient sera on the viral cytopathic effect (CPE), ${ }^{71}$ or the mRNA or protein expression of the IFN $\beta$ responsive gene myxovirus resistance protein $\mathrm{A}(\mathrm{Mx1}) .^{73-75}$

In patients with MS or CD natalizumab ADA is detected with a bridging ELISA screening. Serum samples that are tested positive for antibodies can further be evaluated regarding their neutralizing capacity in a cell-based blocking approach. ${ }^{76,77}$ However, due to a high concordance rate between the two assays, only the bridging-ELISA step is used in clinical routine. ${ }^{77}$

So far ADA testing is not integrated into clinical routine for treatment of RA or CD with antiTNF-antagonist, mainly because NAbs have not yet consistently been associated with LOR. Experimental ADA-testing includes ELISA and RIA methods to screen for ADA (Table 1). Most of these tests also include studying drug levels in parallel to assessment of the functional relevance of ADAs. ${ }^{11}$ Recent cell-based assay such as reporter gene methods are currently evaluated regarding their predictive value for LOR. ${ }^{69}$

\section{Prediction and prevention of anti-drug antibody formation}

In drug development, measures to predict and prevent immunogenicity of a new compound have been developed. Attempts to lower the immunogenicity for e.g. IFN $\beta$ variants by the elimination of an immune-dominant epitope have not yet been successful. ${ }^{78}$ However, many improvements in drug formulations have efficiently reduced the immunogenicity of IFN $\beta .{ }^{79}$ Other strategies have been to reduce the aggregate formation, with as simple approaches as improved storage and handling of the protein product by clinicians and patients. $^{25}$

For selected immunogenicity studies ex vivo cell assays, non-human primate, or transgenic mouse models are used. ${ }^{80}$ Main goal in these models is to be able to already preclinically predict the effect of protein sequence, route of administration, or concomitant medication on immunogenicity, and the clinical relevance of ADA-formation. ${ }^{19}$ Furthermore, animal models are useful tools to further elucidate the mechanisms of ADA-induction. ${ }^{80}$ The analysis of expanded T-cell libraries, ${ }^{81}$ and transgenic mouse models for human HLA, currently explored to predict epitopes for efficient vaccines, ${ }^{82,83}$ are promising recently developed tools to predict immunogenicity. Ex vivo studies include the quantitative analysis of the $\mathrm{CD} 4+$ T-cell repertoire regarding specificity to the therapeutic agent. ${ }^{84}$

To predict the risk of ADA-formation in the individual patients treated, genetic analyses might be promising future approaches. Other biomarkers include e.g. phenotyping the T and B cells as well as DC subsets and future studies will show the prediction value of these phenotype characterizations for ADA-development.

\section{Strategies to deplete persisting anti-drug antibodies}

Antibody concentrations can be reduced by plasma exchange or immunoadsorption. ${ }^{9}$ In conditions where the LOR is associated with fatal consequences and long-term therapy is required - such as in $\mathrm{HA}$ - strategies aiming to induce tolerance to the BP have already been developed. High doses of factor VIII are given over several months to induce tolerance, a principal named induced immune tolerance therapy (ITT). ${ }^{85,86}$ Future approaches, so far mainly tested in HA patients, aim to deplete persisting ADAs and include monoclonal antibodies against IL-17 or IL-17 receptor, ${ }^{87}$ the Tcell co-stimulatory molecule B7,88 the B-cell surface marker CD20, ${ }^{89,90}$ the T-and B-cell surface marker CD52, ${ }^{91}$ or high-affinity anti-idotypic antibodies specifically designed against the main immunogenic domains of a BP such as factor VIII. ${ }^{92}$

Certainly, strategies to deplete ADAs will differ considerably for other diseases and treat- 
ments, when ADA formation is not a potentially life-threatening consequence. Therefore, ITT is not generally considered a practical alternative for drugs that modulate the immune system (e.g. IFN $\beta$ ), although in a pilot study of high doses of i.v. administration of IFN $\beta$ the bioavailability could be restored. ${ }^{93}$ These studies, however, are compromised by the fact that a proportion of patients spontaneously revert to negativity and also regain the clinical effect of the drug, mainly seen in patients with low-positive titers..$^{75,94,95}$ Other strategies, such as methylprednisolone alone or in combination with azathioprine did not have a significant effect on the titer courses in small scale studies and short trial periods of six months..$^{96,97}$ Conversely, in the treatment of CD with infliximab the co-medication with azathioprine or methotrexate was associated with a lower risk of ADA-formation. ${ }^{47,98}$

\section{Conclusions}

Development of ADA is an immunological phenomenon that has to be taken into account in modern medicine. In some fields this is a well-established routine of treatment surveillance, but not in others. The first obvious task to improve the value of immunogenicity studies in clinical practice is a higher level of standardization of ADA testing methods. The different frequency of ADAs reported for different BPs, and in particular for the same BPs in different studies (Table 1), illustrates the complexity of measuring immunogenicity, compromised by different trial design, study populations, assay techniques, timing of measurements, mode of administration and concomitant immunosuppressive medication. ${ }^{11,72,99}$ Measurement of anti-natalizumab antibodies with one highly standardized method results in comparable frequencies in post-marketing studies across different populations. ${ }^{77}$ Nevertheless, also for this test methodological improvements can be discussed, as a bridging ELISA might not detect monovalent IgG4 antibodies that potentially affect the pharmacokinetics of the drug in some individuals. ${ }^{72,100}$

Clearly, the clinical relevance of ADAs to BPs differs across the clinical fields. Therefore, the issues of prevention, prediction, and depletion of ADAs have received varying attention. In HA, where factor VIII treatment is a unique therapy for a life-threatening disease, the acceptable treatment risk might be higher, and cost-intensive efforts are warranted to deplete ADAs. Conversely, although IFN $\beta$ is still first line treatment for patients with MS mainly due to the positive safety profile, various new therapeutic options currently become available. Thus, not the depletion but rather the predic- tion of the LOR due to immunogenicity is an important aim in this field. Importantly, a consensus has already been achieved that patients with high titers of NAbs should be switched to non-IFN $\beta$ treatments in several countries. ${ }^{101}$ However, due to a still existing lack of standardization in ADA testing protocols the cut-off to define high titers of NAbs considerably vary across different centers. ${ }^{72}$

In particular for anti-TNF $\alpha$ BPs, immunogenicity assays seem to produce controversial data, only partly being able to correlate LOR to the presence of ADAs. Techniques need to be established which are able to detect the quantitative and qualitative appearance of ADA in first hand and then secondly in what way this correlate with LOR. Only then, clinicians can decide based on a meaningful result if alternative anti-TNF $\alpha$ BPs could be an option, or a different class of BPs should be tried. ${ }^{11}$

Taking together, our examples from clinical practice illustrate the need of further research on immunogenicity against drugs across different fields in multicenter approaches to standardize assays and to help to predict LOR due to immunogenicity. This could contribute to prevent that a large proportion of patients is exposed to an expensive, but ineffective and potentially harmful therapy.

\section{References}

1. Gupta S, Devanarayan V, Finco D, et al. Recommendations for the validation of cell-based assays used for the detection of neutralizing antibody immune responses elicited against biological therapeutics. J Pharm Biomed Anal 2011; 55:878-88.

2. Gupta S, Indelicato SR, Jethwa V, et al. Recommendations for the design, optimization, and qualification of cell-based assays used for the detection of neutralizing antibody responses elicited to biological therapeutics. J Immunol Methods 2007;321:1-18.

3. Krumbholz M, Pellkofer H, Gold R, et al. Delayed allergic reaction to natalizumab associated with early formation of neutralizing antibodies. Arch Neurol 2007; 64:1331-3.

4. Sominanda A, Lundkvist M, FogdellHahn A, et al. Inhibition of endogenous interferon beta by neutralizing antibodies against recombinant interferon beta. Arch Neurol 2010;67:1095-101.

5. Li J, Yang C, Xia Y, et al. Thrombocytopenia caused by the development of antibodies to thrombopoietin. Blood 2001; 98:3241-8.

6. Casadevall N, Nataf J, Viron B, et al. Pure red-cell aplasia and antierythropoietin antibodies in patients treated with recombinant erythropoietin. $\mathrm{N}$ Engl $\mathrm{J}$ Med 2002;346:469-75.

7. Macdougall IC. Epoetin-induced pure red cell aplasia: diagnosis and treatment. Curr Opin Nephrol Hypertens 2007;16: 585-8.

8. Shankar G, Devanarayan V, Amaravadi L, et al. Recommendations for the validation of immunoassays used for detection of host antibodies against biotechnology products. J Pharm Biomed Anal 2008; 48:1267-81.

9. Green D. Factor VIII inhibitors: a 50-year perspective. Haemophilia 2011;17:831-8.

10. Interferon beta-1b is effective in relapsing-remitting multiple sclerosis. I. Clinical results of a multicenter, randomized, double-blind, placebo-controlled trial. The IFNB Multiple Sclerosis Study Group. Neurology 1993;43:655-61.

11. Yanai H, Hanauer SB. Assessing response and loss of response to biological therapies in IBD. Am J Gastroenterol 2011;106:685-98.

12. Krieckaert C, Rispens T, Wolbink G. Immunogenicity of biological therapeutics: from assay to patient. Curr Opin Rheumatol 2012;24:306-11.

13. Goverman JM. Immune tolerance in multiple sclerosis. Immunol Rev 2011;241: 228-40.

14. Sauerborn M, Brinks V, Jiskoot W, Schellekens H. Immunological mechanism underlying the immune response to recombinant human protein therapeutics. Trends Pharmacol Sci 2010;31:53-9.

15. Astermark J. Why do inhibitors develop? Principles of and factors influencing the risk for inhibitor development in haemophilia. Haemophilia 2006;12:5260 .

16. Ehrenforth S, Kreuz W, Scharrer I, et al Incidence of development of factor VIII and factor IX inhibitors in haemophiliacs. Lancet 1992;339:594-8.

17. Astermark J. Inhibitor development: patient-determined risk factors. Haemophilia 2010;16:66-70.

18. van Haren SD, Wroblewska A, Fischer K, et al. Requirements for immune recognition and processing of factor VIII by antigen-presenting cells. Blood Rev 2012;26: 43-9.

19. Schellekens H. Bioequivalence and the immunogenicity of biopharmaceuticals. Nature reviews Drug discovery 2002;1: 457-62.

20. Banchereau J, Steinman RM. Dendritic cells and the control of immunity. Nature 1998;392:245-52.

21. Nace G, Evankovich J, Eid R, Tsung A. Dendritic cells and damage-associated molecular patterns: endogenous danger 
signals linking innate and adaptive immunity. J Innate Immun 2012;4:6-15.

22. Klechevsky E, Morita R, Liu M, et al. Functional specializations of human epidermal Langerhans cells and CD14+ dermal dendritic cells. Immunity 2008;29: 497-510.

23. Morita R, Schmitt N, Bentebibel SE, et al. Human blood CXCR5(+)CD4(+) T cells are counterparts of $\mathrm{T}$ follicular cells and contain specific subsets that differentially support antibody secretion. Immunity 2011;34:108-21.

24. Goodnow CC, Vinuesa CG, Randall KL, et al. Control systems and decision making for antibody production. Nat Immunol 2010;11:681-88.

25. van Beers MM, Jiskoot W, Schellekens $H$. On the role of aggregates in the immunogenicity of recombinant human interferon beta in patients with multiple sclerosis. J Interferon Cytokine Res 2010;30:767-75.

26. Emi Aikawa N, de Carvalho JF, Artur Almeida Silva C, Bonfa E. Immuno-genicity of anti-TNF-alpha agents in autoimmune diseases. Clin Rev Allergy Immunol 2010;38:82-9.

27. Rudick RA, Sandrock A. Natalizumab: alpha 4-integrin antagonist selective adhesion molecule inhibitors for MS. Expert Rev Neurother 2004;4:571-80.

28. Wight J, Paisley S. The epidemiology of inhibitors in haemophilia A: a systematic review. Haemophilia 2003;9:418-35.

29. Sandborn WJ, Colombel JF, Enns R, et al. Natalizumab induction and maintenance therapy for Crohn's disease. N Engl J Med 2005;353:1912-25.

30. Targan SR, Feagan BG, Fedorak RN, et al. Natalizumab for the treatment of active Crohn's disease: results of the ENCORE Trial. Gastroenterology 2007;132:167283.

31. Maini RN, Breedveld FC, Kalden JR, et al. Therapeutic efficacy of multiple intravenous infusions of anti-tumor necrosis factor alpha monoclonal antibody combined with low-dose weekly methotrexate in rheumatoid arthritis. Arthritis Rheum 1998;41:1552-63.

32. Svenson M, Geborek P, Saxne T, Bendtzen K. Monitoring patients treated with anti-TNF-alpha biopharmaceuticals: assessing serum infliximab and antiinfliximab antibodies. Rheumatology (Oxford) 2007;46:1828-34.

33. Lipsky PE, van der Heijde DM, St Clair $\mathrm{EW}$, et al. Infliximab and methotrexate in the treatment of rheumatoid arthritis. Anti-tumor necrosis factor trial in rheumatoid arthritis with concomitant therapy study group. N Engl J Med 2000; 343:1594-602.
34. Bendtzen K, Geborek P, Svenson M, et al. Individualized monitoring of drug bioavailability and immunogenicity in rheumatoid arthritis patients treated with the tumor necrosis factor alpha inhibitor infliximab. Arthritis Rheum 2006;54:3782-9.

35. Jamnitski A, Krieckaert CL, Nurmohamed MT, et al. Patients nonresponding to etanercept obtain lower etanercept concentrations compared with responding patients. Ann Rheum Dis 2012;71:88-91.

36. Foerder CA, Rogge MC. Enbrel (etanercept). Dev Biol (Basel) 2002;109:99-102.

37. Keystone EC, Schiff MH, Kremer JM, et al. Once-weekly administration of $50 \mathrm{mg}$ etanercept in patients with active rheumatoid arthritis: results of a multicenter, randomized, double-blind, placebo-controlled trial. Arthritis Rheum 2004;50:353-63.

38. Dore RK, Mathews S, Schechtman J, et al. The immunogenicity, safety, and efficacy of etanercept liquid administered once weekly in patients with rheumatoid arthritis. Clin Exp Rheumatol 2007;25: 40-6.

39. Bartelds GM, Wijbrandts CA, Nurmohamed MT, et al. Clinical response to adalimumab: relationship to anti-adalimumab antibodies and serum adalimumab concentrations in rheumatoid arthritis. Ann Rheum Dis 2007;66:921-6.

40. Keystone EC, Kavanaugh AF, Sharp JT, et al. Radiographic, clinical, and functional outcomes of treatment with adalimumab (a human anti-tumor necrosis factor monoclonal antibody) in patients with active rheumatoid arthritis receiving concomitant methotrexate therapy: a randomized, placebo-controlled, 52-week trial. Arthritis Rheum 2004;50:1400-11.

41. Anderson PJ. Tumor necrosis factor inhibitors: clinical implications of their different immunogenicity profiles. Semin Arthritis Rheum 2005;34:19-22.

42. Weinblatt ME, Keystone EC, Furst DE, et al. Adalimumab, a fully human antitumor necrosis factor alpha monoclonal antibody, for the treatment of rheumatoid arthritis in patients taking concomitant methotrexate: the ARMADA trial. Arthritis Rheum 2003;48:35-45.

43. Bender NK, Heilig CE, Droll B, et al. Immunogenicity, efficacy and adverse events of adalimumab in RA patients. Rheumatol Int 2007;27:269-74.

44. Bartelds GM, Krieckaert CL, Nurmohamed MT, et al. Development of antidrug antibodies against adalimumab and association with disease activity and treatment failure during long-term follow-up. JAMA 2011;305:1460-8.
45. Targan SR, Hanauer SB, van Deventer SJ, et al. A short-term study of chimeric monoclonal antibody cA2 to tumor necrosis factor alpha for Crohn's disease. Crohn's Disease cA2 Study Group. N Engl J Med 1997;337:1029-35.

46. Farrell RJ, Alsahli M, Jeen YT, et al. Intravenous hydrocortisone premedication reduces antibodies to infliximab in Crohn's disease: a randomized controlled trial. Gastroenterology 2003;124:917-24.

47. Vermeire S, Noman M, Van Assche G, et al. Effectiveness of concomitant immunosuppressive therapy in suppressing the formation of antibodies to infliximab in Crohn's disease. Gut 2007;56:1226-31.

48. Baert F, Noman M, Vermeire S, et al. Influence of immunogenicity on the long-term efficacy of infliximab in Crohn's disease. N Engl J Med 2003;348: 601-8.

49. Ben-Horin S, Yavzori M, Katz L, et al. The immunogenic part of infliximab is the $\mathrm{F}(\mathrm{ab}) 2$, but measuring antibodies to the intact infliximab molecule is more clinically useful. Gut 2011;60:41-8.

50. Sandborn WJ, Hanauer SB, Rutgeerts P, et al. Adalimumab for maintenance treatment of Crohn's disease: results of the CLASSIC II trial. Gut 2007;56:1232-9.

51. West RL, Zelinkova Z, Wolbink GJ, et al. Immunogenicity negatively influences the outcome of adalimumab treatment in Crohn's disease. Aliment Pharmacol Ther 2008;28:1122-6.

52. Barbosa MD, Vielmetter J, Chu S, et al. Clinical link between MHC class II haplotype and interferon-beta (IFN-beta) immunogenicity. Clin Immunol 2006; 118:42-50.

53. Dasgupta S, Navarrete AM, Bayry J, et al. A role for exposed mannosylations in presentation of human therapeutic selfproteins to CD4+ T lymphocytes. Proc Natl Acad Sci U S A 2007;104:8965-70.

54. Rosendaal FR, Nieuwenhuis HK, van den Berg HM, et al. A sudden increase in factor VIII inhibitor development in multitransfused hemophilia A patients in The Netherlands. Dutch Hemophilia Study Group. Blood 1993;81:2180-6.

55. Ross C, Clemmesen KM, Svenson M, et al. Immunogenicity of interferon-beta in multiple sclerosis patients: influence of preparation, dosage, dose frequency, and route of administration. Danish Multiple Sclerosis Study Group. Ann Neurol 2000; 48:706-12.

56. Peng A, Gaitonde P, Kosloski MP, et al. Effect of route of administration of human recombinant factor VIII on its immunogenicity in Hemophilia A mice. J Pharm Sci 2009;98:4480-4. 
57. Schwaab R, Brackmann HH, Meyer C, et al. Haemophilia A: mutation type determines risk of inhibitor formation. Thromb Haemost 1995;74:1402-6.

58. Tait BD. The ever-expanding list of HLA alleles: changing HLA nomenclature and its relevance to clinical transplantation. Transplant Rev (Orlando) 2011;25:1-8.

59. Hoffmann S, Cepok S, Grummel V, et al. HLA-DRB $1 * 0401$ and HLA-DRB1*0408 are strongly associated with the development of antibodies against interferonbeta therapy in multiple sclerosis. Am J Hum Genet 2008;83:219-27.

60. Buck D, Cepok S, Hoffmann S, et al. Influence of the HLA-DRB1 genotype on antibody development to interferon beta in multiple sclerosis. Arch Neurol 2011; 68:480-7.

61. Pavlova A, Delev D, Lacroix-Desmazes S, et al. Impact of polymorphisms of the major histocompatibility complex class II, interleukin-10, tumor necrosis factoralpha and cytotoxic T-lymphocyte antigen-4 genes on inhibitor development in severe hemophilia A. J Thromb Haemost 2009;7:2006-15.

62. Weber F, Cepok S, Wolf C, et al. Singlenucleotide polymorphisms in HLA- and non-HLA genes associated with the development of antibodies to interferonbeta therapy in multiple sclerosis patients. Pharmacogenomics J 2012;12:238-45.

63. Sorensen PS, Koch-Henriksen N, Jensen PE. Neutralizing antibodies against interferon-beta do not predispose antibodies against natalizumab. Neurology 2011;76:759-60.

64. Dimitrov JD, Dasgupta S, Navarrete AM, et al. Induction of heme oxygenase-1 in factor VIII-deficient mice reduces the immune response to therapeutic factor VIII. Blood 2010;115:2682-5.

65. Pozzilli C, Antonini G, Bagnato F, et al. Monthly corticosteroids decrease neutralizing antibodies to IFNbetal b: a randomized trial in multiple sclerosis. $\mathrm{J}$ Neurol 2002;249:50-6.

66. Mire-Sluis AR, Barrett YC, Devanarayan $\mathrm{V}$, et al. Recommendations for the design and optimization of immunoassays used in the detection of host antibodies against biotechnology products. J Immunol Methods 2004;289:1-16.

67. Wadhwa M, Thorpe R. Unwanted immunogenicity: lessons learned and future challenges. Bioanalysis 2010;2: 1073-84.

68. Wolbink GJ, Aarden LA, Dijkmans BA. Dealing with immunogenicity of biologicals: assessment and clinical relevance. Curr Opin Rheumatol 2009;21:211-5.

69. Lallemand C, Kavrochorianou N,
Steenholdt C, et al. Reporter gene assay for the quantification of the activity and neutralizing antibody response to TNFalpha antagonists. J Immunol Methods 2011;373:229-39.

70. Verbruggen B, van Heerde WL, Laros-van Gorkom BA. Improvements in factor VIII inhibitor detection: from Bethesda to Nijmegen. Semin Thromb Hemost 2009; 35:752-9.

71. Deisenhammer F, Schellekens H, Bertolotto A. Measurement of neutralizing antibodies to interferon beta in patients with multiple sclerosis. J Neurol 2004;251:II31-39.

72. Bendtzen K. Critical review: assessment of interferon-beta immunogenicity in multiple sclerosis. J Interferon Cytokine Res 2010;30:759-66.

73. Bertolotto A, Gilli F, Sala A, et al. Evaluation of bioavailability of three types of IFNbeta in multiple sclerosis patients by a new quantitative-competitive-PCR method for MxA quantification. J Immunol Methods 2001;256:141-52.

74. Killestein J, Polman CH. Determinants of interferon beta efficacy in patients with multiple sclerosis. Nat Rev Neurol 2011;7:221-8.

75. Sominanda A, Hillert J, Fogdell-Hahn A. In vivo bioactivity of interferon-beta in multiple sclerosis patients with neutralising antibodies is titre-dependent. $\mathrm{J}$ Neurol Neurosurg Psychiatry 2008;79:5762.

76. Calabresi PA, Giovannoni G, Confavreux $\mathrm{C}$, et al. The incidence and significance of anti-natalizumab antibodies: results from AFFIRM and SENTINEL. Neurology 2007;69:1391-403.

77. Sorensen PS, Jensen PE, Haghikia A, et al. Occurrence of antibodies against natalizumab in relapsing multiple sclerosis patients treated with natalizumab. Mult Scler 2011;17:1074-78.

78. Yeung VP, Chang J, Miller J, et al. Elimination of an immunodominant CD4+ T cell epitope in human IFN-beta does not result in an in vivo response directed at the subdominant epitope. $\mathrm{J}$ Immunol 2004;172:6658-65.

79. Giovannoni G, Barbarash 0, CassetSemanaz F, et al. Safety and immunogenicity of a new formulation of interferon beta-1a (Rebif New Formulation) in a Phase IIIb study in patients with relapsing multiple sclerosis: 96-week results. Mult Scler 2009;15:219-28.

80. Brinks V, Jiskoot W, Schellekens H. Immunogenicity of therapeutic proteins: the use of animal models. Pharm Res 2011;28:2379-85.

81. Geiger R, Duhen T, Lanzavecchia A, Sallusto F. Human naive and memory
CD4+ T cell repertoires specific for naturally processed antigens analyzed using libraries of amplified T cells. J Exp Med 2009;206:1525-34.

82. Bayard F, Malmassari S, Deng Q, et al. Hepatitis B virus (HBV)-derived DRB1*0101-restricted CD4 T-cell epitopes help in the development of HBVspecific CD8+ T cells in vivo. Vaccine 2010;28:3818-26.

83. Pajot A, Michel ML, Fazilleau N, et al. A mouse model of human adaptive immune functions: HLA-A2.1-/HLA-DR1transgenic $\mathrm{H}-2$ class I-/class II-knockout mice. Eur J Immunol 2004;34:3060-9.

84. Delluc S, Ravot G, Maillere B. Quantitative analysis of the CD4 T-cell repertoire specific to therapeutic antibodies in healthy donors. Faseb $\mathrm{J} 2011$; 25:2040-8.

85. Brackmann HH, Gormsen J. Massive factor-VIII infusion in haemophiliac with factor-VIII inhibitor, high responder Lancet 1977;2:933.

86. DiMichele DM, Hoots WK, Pipe SW, et al. International workshop on immune tolerance induction: consensus recommendations. Haemophilia 2007;13:1-22.

87. de Latour RP, Visconte V, Takaku T, et al Th17 immune responses contribute to the pathophysiology of aplastic anemia. Blood 2010;116:4175-84.

88. Hausl C, Ahmad RU, Schwarz HP, et al. Preventing restimulation of memory $B$ cells in hemophilia A: a potential new strategy for the treatment of antibodydependent immune disorders. Blood 2004;104:115-22.

89. Saito K, Nawata M, Iwata S, et al Extremely high titer of anti-human chimeric antibody following re-treatment with rituximab in a patient with active systemic lupus erythematosus. Rheumatology (Oxford) 2005;44:1462-4.

90. van den Bemt BJ, Vos K, den Broeder AA et al. A single course of rituximab does not abrogate anti-infliximab antibodies in patients with rheumatoid arthritis. Ann Rheum Dis 2009;68:1368-9.

91. Gomez-Almaguer D, Solano-Genesta M, Tarin-Arzaga L, et al. Low-dose rituximab and alemtuzumab combination therapy for patients with steroid-refractory autoimmune cytopenias. Blood 2010;116 4783-5.

92. Gilles JG, Grailly SC, De Maeyer M, et al In vivo neutralization of a $\mathrm{C} 2$ domainspecific human anti-Factor VIII inhibitor by an anti-idiotypic antibody. Blood 2004;103:2617-23

93. Millonig A, Rudzki D, Holzl M, et al. High-dose intravenous interferon beta in patients with neutralizing antibodies (HINABS): a pilot study. Mult Scler 
2009;15:977-83.

94. Sorensen PS, Koch-Henriksen N, Flachs EM, Bendtzen K. Is the treatment effect of IFN-beta restored after the disappearance of neutralizing antibodies? Mult Scler 2008;14:837-42.

95. Gneiss C, Koudouovoh-Tripp PM, Ropele $\mathrm{S}$, et al. Influence of interferon-beta therapy switching on neutralizing antibody titres: results from the Austrian Switch Study. Mult Scler 2009;15:1481-8.

96. Hesse D, Frederiksen JL, KochHenriksen N, et al. Methylprednisolone does not restore biological response in multiple sclerosis patients with neutralizing antibodies against interferon-beta. Eur J Neurol 2009;16:43-7.

97. Ravnborg M, Bendtzen K, Christensen 0, et al. Treatment with azathioprine and cyclic methylprednisolone has little or no effect on bioactivity in anti-interferon beta antibody-positive patients with multiple sclerosis. Mult Scler 2009;15:323-8.

98. Ordas I, Mould DR, Feagan BG, Sandborn WJ. Anti-TNF monoclonal antibodies in inflammatory bowel disease: pharmacokinetics-based dosing paradigms. Clin Pharmacol Ther 2012;91:635-46.
99. Cassinotti A, Travis S. Incidence and clinical significance of immunogenicity to infliximab in Crohn's disease: a critical systematic review. Inflamm Bowel Dis 2009;15:1264-75.

100. Hart MH, de Vrieze H, Wouters D, et al. Differential effect of drug interference in immunogenicity assays. J Immunol Methods 2011;372:196-203.

101. Polman CH, Bertolotto A, Deisenhammer F, et al. Recommendations for clinical use of data on neutralising antibodies to interferon-beta therapy in multiple sclerosis. Lancet Neurol 2010;9:740-50. 